\title{
Clinical and Etiological Profile of Patients with Atrial Fibrillation (AF): Analysis and implications
}

\author{
Mandal RN*1, Mishra AK¹, Mandal EL2 \\ Kyrgyz State Medical Institute of Postgraduate and Continuous Education \\ Ministry of Health, The Kyrgyz Republic
}

${ }^{1}$ Associate Professor, Department of Internal Medicine, Janaki Medical College, Janakpur, Nepal

${ }^{2}$ Senior consultant and Neurologist, Cardio-Neuro centre, Kadam chowk, Janakpurdham, Nepal

\begin{abstract}
Background and Objectives: Atrial fibrillation (AF) is a frequently encountered cardiac arrhythmia which may be either symptomatic or asymptomatic. So, this study was conducted to know clinical presentation and to find out possible clinical and etiological profile of patients with AF .

Material and Methods: This cross sectional study was conducted at Osh Regional Integrated Clinical Hospital, Osh Territorial City Clinical Hospital, The Kyrgyz Republic in collaboration with Janaki Medical College Teaching Hospital, Janakpurdham, Nepal. Sixty consecutive patients with AF were taken. Presenting complaints, past history, personal history was recorded. A thorough clinical examination was done, electrocardiogram, chest X-Ray posterio-anterior view, echocardiogram, thyroid function test and relevant test were done and analyzed.
\end{abstract}

Results: Forty percent of the patients complained palpitation. Systemic thrombo-embolism was found in $15 \%$ of the patients. Other presenting complaints were cough, chest pain, shortness of breath, dizziness, swelling of the legs, tremors. Eighteen percent of patients presented with features of congestive cardiac failure and $30 \%$ of the patients gave history of rheumatic heart disease, $16.6 \%$ and $11.6 \%$ hypertension and ischemic heart disease respectively. Etiology-wise, rheumatic heart disease was the most common (46.6\%) followed by hypertension $(21.6 \%)$, ischemic heart disease (11.6\%), dilated cardiomyopathy (6.6\%), hyperthyroidism (5\%), pneumonia (5\%).

Conclusion: Rheumatic heart disease, especially mitral stenosis is the most common cause of AF in this study. Systemic hypertension was next common etiology of AF, followed by ischaemic heart disease, dilated cardiomyopathy, thyroid disease. Heart failure, Systemic thromboembolism, decreased exercise tolerance are a major determinants for development of significant morbidity and mortality.

Key Words: Atrial fibrillation, cardiac arrhythmia, IHD, Rheumatic Heart disease

INRODUCTION

Atrial fibrillation (AF) is a frequently encountered cardiac arrhythmia. The overall chance of AF developing over a period of two decades in patients older than 30 years, according to Framingham data, is 2 percent. Approximately $4 \%$ of the population over age 60 years has sustained $\mathrm{AF}$, with a particularly 
steep increase in prevalence after the seventh decade of life [1-2]. The most powerful predictor for risk of this arrhythmia in the past was rheumatic heart disease, but since this diagnosis is rare in developed countries, it accounts for only a small number of cases [3]. A history of congestive heart failure, valvular heart disease and stroke, left atrial enlargement, abnormal mitral or aortic valve function, treated systemic hypertension, and advanced age was independently associated with the prevalence of AF [4]. But in an Indian studies common etiology of $\mathrm{AF}$ is rheumatic heart disease [5]. So, younger people with rheumatic heart disease are also vulnerable for development of this arrhythmia in developing countries.

Atrial Fibrillation may be symptomatic or asymptomatic. Though symptomatic AF is more common, a patient's description and tolerance of AF may vary depending on ventricular rate and regularity, the presence of other cardiac disease, and other medical conditions [6]. Perhaps the most common symptom of AF is the sense of a rapid heartbeat or palpitations, which may occur at rest or only after exercise or stress. Dyspnea, fatigue, presyncope, and dizziness are not uncommon. Additionally, chest pain, symptoms of worsening CHF, and symptoms associated with embolism, especially stroke, may be presenting features. So, this study was planned to know clinical presentation and to find out possible clinical and etiological profile of patients with AF.

\section{MATERIALS AND METHODS}

This study was carried out during period of March 2012 to August 2012 in Osh Regional Integrated Clinical Hospital, Osh Territorial City Clinical Hospital, The Kyrgyz Republic in collaboration with Janaki Medical College
Teaching Hospital, Janakpurdham, Nepal. Clinical profile, thyroid function test, chest radiograph, electrocardiogram and echocardiography of patients with AF were taken following standard procedure of hospital. Patients enrolled in study were those visiting outpatient departments, emergency and admitted in wards.

A 12-lead surface electrocardiogram was obtained from each patient and analyzed [4, 7-8]. Chest X-ray postero-anterior view was taken in each case and studies for presence of any abnormality. Criteria for abnormalities were as discussed elsewhere [9].

Transthoracic echocardiogram by M-mode, 2dimentional and doppler echocardiography were done by first author using conventional method and measurements were taken according to recommendation of American society of echocardiography [10]. Twodimensional echocardiographic views were obtained and nomenclature and image orientation was according to the American society of echocardiography [11]. Serum $\mathrm{fT}_{3}$, $\mathrm{fT}_{4}, \mathrm{TSH}$ was measured in all patients except in patients with rheumatic heart disease. Hormonal assay was performed by Serozyme technology, BioChem Immuno Systems Italia S.P.A. made in Italy. Mean and standard deviation were obtained by using SPSS 20.0 for windows.

\section{RESULTS}

The mean age of the study group was $47.77 \pm$ 19.05 (means \pm 1 standard deviation). The age and sex distribution of the patient are shown in table 1 . Out of total number 60 , numbers of female were $33(55 \%)$ and numbers of male were $27(45 \%)$. Patients of the atrial fibrillation were presented with the features presented in Table 2. 
Table 1: Age group and sex wise distribution of patients $(\mathrm{N}=60)$

\begin{tabular}{|l|c|c|c|}
\hline \multicolumn{1}{|c|}{ Age group } & Male & Female & Total \\
\hline 15-20 years & 1 & 3 & 4 \\
\hline 21-30 years & 4 & 5 & 9 \\
\hline 31-40 years & 3 & 9 & 12 \\
\hline 41-50 years & 4 & 4 & 8 \\
\hline 51-60 years & 5 & 4 & 9 \\
\hline 61-70 years & 6 & 4 & 10 \\
\hline 71-80 years & 3 & 3 & 6 \\
\hline$>80$ years & 1 & 1 & 2 \\
\hline Total & $\mathbf{2 7}$ & $\mathbf{3 3}$ & $\mathbf{6 0}$ \\
\hline
\end{tabular}

Table 2: Clinical presentation of the patients $(\mathrm{N}=60)$

\begin{tabular}{|c|l|c|c|}
\hline $\begin{array}{c}\text { S. } \\
\text { N. }\end{array}$ & \multicolumn{1}{|c|}{$\begin{array}{c}\text { Clinical } \\
\text { Presentation }\end{array}$} & $\begin{array}{c}\text { Number } \\
\text { of } \\
\text { Patients }\end{array}$ & Percentage \\
\hline $\mathbf{1 .}$ & Palpitation & 24 & $40 \%$ \\
\hline $\mathbf{2 .}$ & Cough & 18 & $30 \%$ \\
\hline $\mathbf{3 .}$ & Tremor & 16 & $26,6 \%$ \\
\hline $\mathbf{4 .}$ & Abdominal Pain & 15 & $25 \%$ \\
\hline $\mathbf{5 .}$ & Leg Swelling & 14 & $23.3 \%$ \\
\hline $\mathbf{6 .}$ & Dizziness & 14 & $23.3 \%$ \\
\hline $\mathbf{7 .}$ & Chest Pain & 13 & $21.6 \%$ \\
\hline $\mathbf{8 .}$ & Dyspnea & 12 & $20 \%$ \\
\hline $\mathbf{9 .}$ & Sputum Production & 12 & $20 \%$ \\
\hline $\mathbf{1 0 .}$ & Others & 12 & $20 \%$ \\
\hline $\mathbf{1 1 .}$ & Excessive Sweating & 11 & $18.3 \%$ \\
\hline $\mathbf{1 2 .}$ & Orthopnea & 9 & $15 \%$ \\
\hline $\mathbf{1 3 .}$ & Thromboembolism & 9 & $15 \%$ \\
\hline $\mathbf{1 4}$. & Orthopnea & 7 & $11.6 \%$ \\
\hline $\mathbf{1 5}$. & Weight Loss & 6 & $10 \%$ \\
\hline $\mathbf{1 6 .}$ & Heat Intolerance & 5 & $8.3 \%$ \\
\hline $\mathbf{1 7 .}$ & PND & 3 & $5 \%$ \\
\hline $\mathbf{1 8}$. & Haemoptysis & 3 & $5 \%$ \\
\hline
\end{tabular}

Table 3: Past history of the patients

\begin{tabular}{|c|c|}
\hline History & Number (\%) \\
\hline RHD & $18(30 \%)$ \\
\hline IHD & $7(11.6 \%)$ \\
\hline Hypertension & $10(16.6 \%)$ \\
\hline Diabetes & $10(16.6 \%)$ \\
\hline Hyperthyroidism & $0(0 \%)$ \\
\hline
\end{tabular}

Table 3 depicts the past history of the patient whereas table 4, 5, 6 and 7 shows the detail of chest-x-ray, ECG and Echocardiographic findings and Echochardiographic impression respectively.

Table 4: Chest $\mathrm{X}$ - ray findings of the patients $(\mathrm{N}=60)$

\begin{tabular}{|l|c|c|}
\hline \multicolumn{1}{|c|}{$\begin{array}{c}\text { Chest X-Ray } \\
\text { findings }\end{array}$} & $\begin{array}{c}\text { Number of } \\
\text { patients }\end{array}$ & Percentage \\
\hline No Cardiomegaly & 10 & $16.6 \%$ \\
\hline $\begin{array}{l}\text { Evidence of LA } \\
\text { Enlargement }\end{array}$ & 24 & $40 \%$ \\
\hline LV Enlargement & 14 & $23.3 \%$ \\
\hline RV Enlargement & 18 & $30 \%$ \\
\hline $\begin{array}{l}\text { Prominent } \\
\text { pulmonary conus }\end{array}$ & 22 & $36.6 \%$ \\
\hline $\begin{array}{l}\text { Biventricular } \\
\text { Enlargement }\end{array}$ & 13 & $21.6 \%$ \\
\hline $\begin{array}{l}\text { Consolidation of } \\
\text { Pneumonitis }\end{array}$ & 14 & $23.3 \%$ \\
CXR = Chest X-Ray, LA = Left atrium, LV = Left ventricle, \\
RV = Right ventricle
\end{tabular}

Table 5: Showing electrocardiographic findings of the patients $(\mathrm{N}=60)$

\begin{tabular}{|l|c|c|}
\hline \multicolumn{1}{|c|}{ ECG findings } & $\begin{array}{c}\text { Number of } \\
\text { patients }\end{array}$ & Percentage \\
\hline LA abnormality & 32 & $53.3 \%$ \\
\hline LV enlargement & 18 & $30 \%$ \\
\hline RV enlargement & 8 & $13.3 \%$ \\
\hline Left bundle branch block & 7 & $11.6 \%$ \\
\hline Left anterior hemi block & 5 & $8.3 \%$ \\
\hline $\begin{array}{l}\text { Left posterior hemi } \\
\text { block }\end{array}$ & 2 & $3.3 \%$ \\
\hline $\begin{array}{l}\text { Non-specific conduction } \\
\text { block }\end{array}$ & 5 & $8.3 \%$ \\
\hline $\begin{array}{l}\text { Significant ST-Twave } \\
\text { abnormality }\end{array}$ & 10 & $16.6 \%$ \\
\hline Abnormal Q Waves & 5 & $8.3 \%$ \\
\hline
\end{tabular}

After analysis of history, clinical examination and study of ECG, chest X-ray, echocardiogram and thyroid function test, probable etiologies of atrial fibrillation are identified as: RHD in 28(46.66\%); Hypertension in $13(21.66 \%)$; IHD in 7(11.66\%); DCM in 4(6.66\%); Thyrotoxicosis in $3(5 \%)$; pneumonia in $3(5 \%)$; cause undetermined in $2(3.33 \%)$ patients (figure 1$)$ 
Table 6: Trans - thoracic echocardiographic findings of the patients $(\mathrm{N}=60)$

\begin{tabular}{|c|c|c|}
\hline Echocardiographic findings & $\begin{array}{l}\text { Number of } \\
\text { patients }\end{array}$ & Percentage \\
\hline \multicolumn{3}{|l|}{ Left atrial size } \\
\hline Normal $(<4.0 \mathrm{~cm})$ & 18 & $30 \%$ \\
\hline Mild enlargement $(4.1-4.5 \mathrm{~cm})$ & 12 & $20 \%$ \\
\hline $\begin{array}{l}\text { Moderate enlargement (4.6- } \\
5.5 \mathrm{~cm})\end{array}$ & 13 & $21.6 \%$ \\
\hline $\begin{array}{l}\text { Severe enlargement }(>5.5 \\
\mathrm{cm})\end{array}$ & 17 & $28.3 \%$ \\
\hline \multicolumn{3}{|l|}{ Mitral valve abnormality } \\
\hline Thickening & 26 & $43.3 \%$ \\
\hline Stenosis & 24 & $40 \%$ \\
\hline Regurgitation $(>2+/ 4+)$ & 12 & $20 \%$ \\
\hline Mitral annular calcification & 6 & $10 \%$ \\
\hline Prolapse & 2 & $3.3 \%$ \\
\hline LV hypertrophy/dilatation & 22 & $36.6 \%$ \\
\hline \multicolumn{3}{|l|}{ RV and RA } \\
\hline a) Normal & 26 & $43.3 \%$ \\
\hline b) Dilatation / Hypertrophy & 24 & $40 \%$ \\
\hline \multicolumn{3}{|l|}{ Pulmonary arterial pressure } \\
\hline a) Normal & 28 & $46.66 \%$ \\
\hline b) Raised & 32 & $53.3 \%$ \\
\hline \multicolumn{3}{|l|}{ LV ejection fraction } \\
\hline a) $>50 \%$ & 45 & $75 \%$ \\
\hline b) $40-49 \%$ & 8 & $13.3 \%$ \\
\hline c) $30-39 \%$ & 4 & $6.6 \%$ \\
\hline d) $<30 \%$ & 3 & $5 \%$ \\
\hline \multicolumn{3}{|l|}{ LV wall motion abnormality } \\
\hline a) Global & 3 & $5 \%$ \\
\hline b) Regional & 9 & $15 \%$ \\
\hline Diastolic dysfunction & 22 & $36.6 \%$ \\
\hline
\end{tabular}

Table 7: Echocardiographic impression of the patients $(\mathrm{N}=60)$

\begin{tabular}{|c|c|c|}
\hline Impression & $\begin{array}{c}\text { No of } \\
\text { cases }\end{array}$ & Percentage \\
\hline Rheumatic heart disease & 28 & 46.66 \\
\hline Ischaemic heart disease & 7 & 11.6 \\
\hline Concentric LV hypertrophy & 11 & 18.33 \\
\hline Dilated cardiomyopathy & 3 & 5 \\
\hline Cor pulmonale & 6 & 10 \\
\hline No significant finding & 5 & 8.33 \\
& & \\
\hline
\end{tabular}

\section{DISCUSSION}

The mean age of the patients in this study was $54.68 \pm 17.48$ years which was slightly less than that of patients enrolled in AFFIRM study [12], with the mean age of $69.7 \pm 9.0$. In study by Gurpal Singh et al mean age was 51.68 years [5]. In another study of prevalence and management of AF Stewart FM et. al [13], mean age of the patients was 76 years.

A review of four population-based surveys showed the median age of patients with $\mathrm{AF}$ was 75 . The prevalence of $\mathrm{AF}$ was $2.3 \%$ among people over 40 years of age, but $5.9 \%$ among people over age 65 [14]. In addition, the surveys revealed that $70 \%$ of all people with AF are between 65 to 85 years old. Age distribution of patient shows highest number of patients in 31-40 years age group in this study but in developed countries AF is more common in older age group [14]. Explanation can be high incidence and prevalence of rheumatic fever in developing country like Nepal. Total number of male was $27(45 \%)$ while numbers of female were $33(55 \%)$. In this study there is female prepondance as it was seen in study done by Gurpal Singh et al [3] in which among 66 patients, 31 (47\%) were male; 35 (53\%) were females. In study of Stewart et al [13] among one hundred and forty-seven patients there were $52 \%$ male and $48 \%$ female with mean age 76 years.

Very limited data are available on clinical presentation of the condition for comparison with this study. Palpitation was commonest presenting complaint found in 24 (40\%) out of 60 patients. In CARAF registry, palpitation was noted in as much as $50 \%$ of the patients. It was more in patients with rapid ventricular response and new onset AF [15]. Second common symptom was cough, found in 


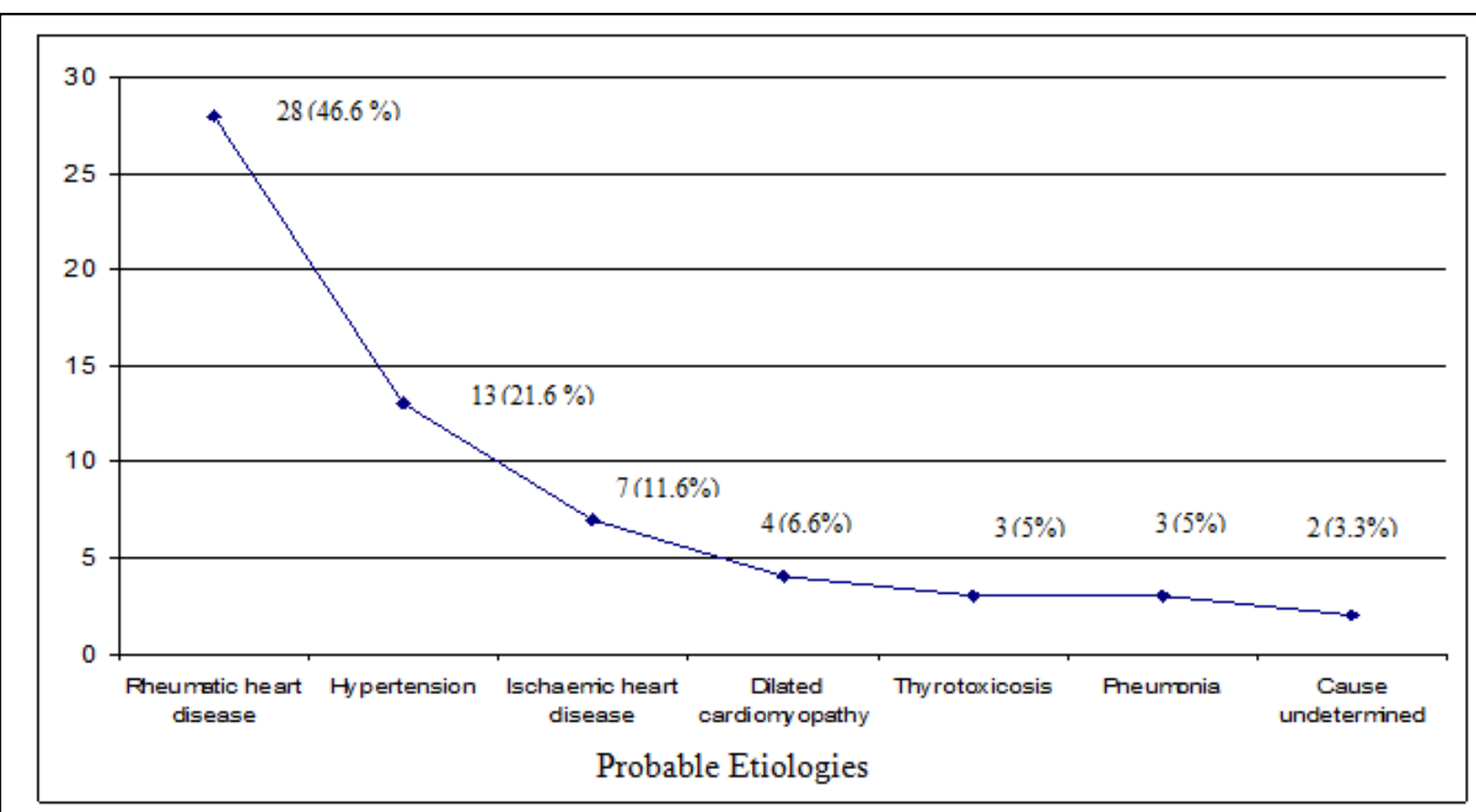

Fig 1: Line diagram showing probable etiologies of Atrial fibrillation (AF) in this study

$18(30 \%)$ of the patients of this study. This includes cough related with pulmonary congestion due to elevated left atrial pressure secondary to mitral valve disease, heart failure, and respiratory tract infection. Infectious aetiology was indicated by presence of pluritic type chest pain, of purulent sputum, and pneumonitis or consolidation in chest radiograph. In $20 \%$ of the patients cough was productive, in about half of those sputum was purulent. Pneumonitis or consolidation was noted in $14(23.3 \%)$ patients in chest radiograph study. Study by Stewart et al among 147 patients CAF, cause of admission was pneumonia in $17 \%$ cases. [13].

The fine postural tremor was found in $16(26.6 \%)$ out of 60 patients. These might have included exaggerated physiological tremor with advancing age. Abdominal pain was found in $15(25 \%)$ patients. In most of them pain was epigastric in location and burning type without any radiation. This included pain resulting from congestion secondary to right heart failure and concomitant acid peptic disease. Dizziness was found in $14(23.3 \%)$ patients. In CARAF registry dizziness was found in $25 \%$ of the patients [15]. Leg swelling was present in $14(23.3 \%)$ patients. In this group of patient there were other features of right heart failure. Chest pain was presenting complaint in $13(21.6 \%)$ patients. $10(16.6 \%)$ of them gave, retro-sternal pressing type of chest pain which was aggravated by exertion. Rest of 3 patients gave history of typical pluritic type, which was made worse on coughing and deep breathing. Dyspnea was noted in 12(20\%) patients. It used to get aggravated by exertion. $7(11.6 \%)$ of them gave history suggestive of orthopnea and $3(5 \%)$ gave history of paroxysmal nocturnal dyspnea. In CARAF registry dyspnea was found in less than $20 \%$ of the patients [15].

Systemic thromboembolism has received most attention regarding clinical outcome of the AF. Systemic thromboembolism was noted in $9(15 \%)$ patients. Six of them had 
hemiplegia with suggestive ischaemic changes in middle cerebral artery territory in CT scan of head. In 2 patients, CT scan was normal. Out of total 9 patients, 4 had rheumatic heart disease, 3 had hypertension, one had biventricular heart failure. Among 9 patients 3 were receiving aspirin but none of them were on warfarin. Although sample size was small there was no thromboembolism in warfarin group. A number of trials have reported an association between clinical parameters and the risk of stroke in $\mathrm{AF}$ patients [16]. The thromboembolism rate was $1 \%$, when no risk factors were present, $6.0 \%$ when one or two factors were present and $18.6 \%$ when three or more were present. Excessive sweating was found in 11(18.3\%) patients. There was weight loss in $6(10 \%)$ patients despite average appetite. 5(8.3\%) patients volunteered heat intolerance. In treatment history, aspirin was the most frequently used drug 25(41.6\%), followed by antiarrhythmic drug 22(36.6\%). Warfarin was used in $7(11.6 \%)$.

In this study, etiologically rheumatic heart disease was most common seen in $28(46.66 \%)$ out of 60 patients. In study done by Gurpal singh RHD was found in 37.8\% [5]. There are only a few western literatures relating rheumatic heart disease and AF. This may be due to relatively low prevalence of rheumatic heart disease in developed countries [1-2]. Next common etiology was hypertension that was found in $13(12.6 \%)$ patients. Mean left atrial size in these patients was $5.21 \pm 0.32$. Hypertension was found in $13.63 \%$ patients in Singh's study [5]. In a study of Kannel WB et.al, hypertension was found in $45 \%$ of the patients with AF [17]. In AFFIRM study, out of 4060 patients enrolled, 51\% were hypertensives [12].
Ischemic heart disease was next common etiology noted. This entity was determined by presence of abnormal $Q$ waves, $T$ wave inversion, a new onset bundle branch block in absence of other likely explanation, wall motion abnormality in two-dimensional echocardiogram. In this study ischaemic heart disease was found as $7(11.6 \%)$ of the patients. Two of the 7 patients were admitted with the diagnosis of acute myocardial infarction. In Singh et.al study, IHD was found in 3.3\% patients [5]. Among patients enrolled in AFFIRM study coronary artery disease was present in 26\% [12]. In the study of Stewart et.al ischaemic heart disease was found in $11 \%$ of the patients admitted with AF [13]. Approximately $25 \%$ of patients with AF have coronary artery disease as an antecedent diagnosis [17].

Dilated cardio-myopathy (DCM) was seen in $4(6.6 \%)$ of the patients. Diagnostic criteria for dilated cardio-myopathy was adopted as left ventricular ejection fraction <40\%, LVEDD> $112 \%$ of predicted and fractional shortening $<25 \%$. According to Singh et.al [5], DCM was found in $22.72 \%$ patients. In AFFIRM study cardio-myopathy was predominant diagnosis in $5 \%$ of the patients [12].

Thyrotoxicosis was found in $3(5 \%)$ of the patients in this study. Other clinical features present in these patients, were heat intolerance, tremor, warm and moist palms. In Gurpal Singh et.al, Thyrotoxicosis was found in $9.09 \%$ of the patients. Krahn AD et.al stated that thyroid disease is an unusual and sometimes overlooked cause of AF, occurring in about $2 \%$ of patients [18].

In $3(5 \%)$ patients Pneumonia was the associated condition with AF in this study. In Stewart et.al study, pneumonia was the cause for admission in $17 \%$ of the patients [13]. 
Similarly, in $2(3.3 \%)$ patients no cause was found. In Gurpal Singh et.al 1.5\% patients were reported as lone AF [5].

\section{CONCLUSION}

$\mathrm{AF}$ was commonly seen in females. About $1 / 3^{\text {rd }}$ of the cases had past history of RHD, other risk factors were hypertension, IHD, DCM, hyperthyroidism, pneumonia. Left atrial enlargement was commonest Echo cardiographic findings.

\section{ACKNOWLEDGEMENT}

We are grateful to Prof. Kshitiz Upadhyay Dhungel, Director- Think Tank Foundation and Dr. Nabin Lageju, Assist. Professor, Department of ENT, JMCTH for taking pain to go through the manuscript for revision and for their valuable suggestions.

\section{AUTHOR'S CONTRIBUTION:}

RNM- Data collection, drafting first draft of manuscript, data analysis and final approval; AKM- Data collection, revision of first draft; ELM- Intellectual discussions and revision of final manuscript prepared.

SOURCE OF SUPPORT: Logistic and clinical support, Kyrgyz State Medical Institute of Postgraduate and Continuous Education, Ministry of Health, The Kyrgyz Republic and Janaki Medical College teaching Hospital, Janakpur, Nepal.

CONFLICT OF INTEREST: None declared.

\section{REFERENCES}

1. Benjamin EJ, Levy D, Vaziri SM, et al: Independent risk factors for atrial fibrillation in a population-based cohort. The Framingham Heart Study. JAMA 1994; 241:840-844.
2. Kennel WB, Abbott RD, Savage DD, et al: Epidemiologic features of chronic atrial fibrillation: The Framingham study. N Engl J Med 1982; 306:1018-1022.

3. Diagnosis and treatment of tachyarrhythmias, In Goldman and Braunwald: Primary Cardiology, 1st ed. W.B. Saunders Company; 1998.

4. Braunwald. Heart Disease: A Textbook of Cardiovascular Medicine, $6^{\text {th }}$ eds. W.B. Saunders Company; 2001.

5. Gurpal Singh et.al. A study of 66 patients of atrial fibrillation (AF)-Clinical and Etiological review. J of Association of Physicians of India 2001; 49.

6. Levy S, Breithardt G. Campbell RWF et al: Atrial fibrillation: Current knowledge and recommendations for management. Eur Heart J 1998; 19: 1294-1320.

7. Goldberger AL: The genesis of indeterminate axis: A quantitative vector-cardiographic analysis. J Electrocardiol 1982; 15:221-226.

8. Murphy ML, Thenabadu PN, De Soyza N, et al. Re-evaluation of electrocardiographic criteria for left, right and combined cardiac ventricular hypertrophy. Am J Cardiol 1984; 53:11411147.

9. Grainger \& Allison. Diagnostics Radiology: A Textbook of Medical Imaging, $4^{\text {th }}$ eds. Churchill Livingstone, Inc 2001.

10. Shah DJ, Demania A, Kisslo J and Weyman A. Recommendation regarding quantitation in echocardiographic measurement. Circulation 1979; 59:1024.

11. Henry WL, DeMaria A, Gramiat R et.al. Report of the American society of echocardiography committee on nomenclature and standard in 2-dimentional echocardiography. Circulation 1980; 62:212.

12. Baseline characteristics of patients with atrial fibrillation: The AFFIRM Study. American Heart Journal 2002; 143(6):991-1001.

13. Stewart FM, Singh Y, Persson S, Gamble GD, Braatvedt GD. Atrial fibrillation: prevalence and management in an acute general medical unit. Australian and New Zealand J Med 1999; 29(4): 568

14. Feinberg WM, Blackshear JL, Laupacis A et al. Prevalence, age distribution, and gender of patients with atrial fibrillation: Analysis and implications. Arch Intern Med 1995; 155:469473. 
15. Kerr CR. The Canadian registry of atrial fibrillation; who wants to be treated for atrial fibrillation? Relation of clinical variable to symptoms, In: Murgatroyd FD, camm AJ ed. Armonk, NY. Non-pharmacological management of atrial fibrillation. Futura Publication company; 1997. pp 15-22.

16. Stroke Prevention in Atrial Fibrillation Investigators. Predictors of thromboembolism in atrial fibrillation. Ann Intern Med 1992; 116:6.

17. Kannel WB, Wolf PA. Epidemiology of atrial fibrillation. In: Falk RH, Podrid PJ, (eds). Atrial Fibrillation; Mechanism and Management. Raven Press: New York; 1992. pp 81-92.

18. Krahn AD, Klein GJ, Kerr CR, et al: How useful is thyroid function testing in patients with recent-onset atrial fibrillation? The Canadian Registry of Atrial Fibrillation investigators. Arch Intern Med 1996; 156: 2221-2224.

Correspondence to; Dr. Ram Narayan Mandal

Associate Professor Department of Medicine Janaki Medical College, Janakpur Email: elmarama1967@yahoo.com 